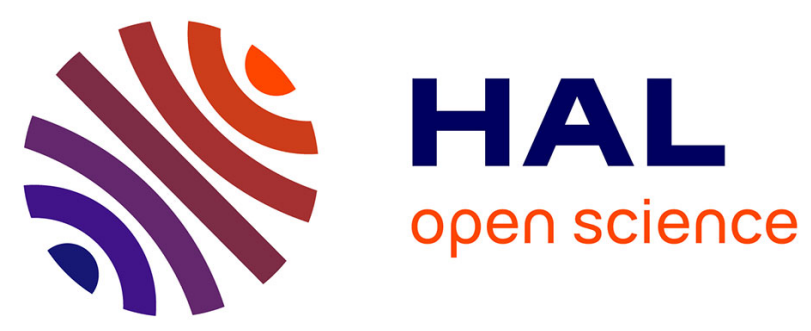

\title{
Towards contact integration for III-V/Silicon heterogeneous photonics devices
}

Elodie Ghegin, Philippe Rodriguez, F Nemouchi, Ch Jany, M. Brihoum, A. Halimaoui, I. Sagnes, B Szelag

\section{- To cite this version:}

Elodie Ghegin, Philippe Rodriguez, F Nemouchi, Ch Jany, M. Brihoum, et al.. Towards contact integration for III-V/Silicon heterogeneous photonics devices. 2016 IEEE International Interconnect Technology Conference / Advanced Metallization Conference (IITC/AMC), May 2016, San Jose, United States. pp.69 - 71, 10.1109/IITC-AMC.2016.7507684 . cea-01615818

HAL Id: cea-01615818 https://hal-cea.archives-ouvertes.fr/cea-01615818

Submitted on 12 Oct 2017

HAL is a multi-disciplinary open access archive for the deposit and dissemination of scientific research documents, whether they are published or not. The documents may come from teaching and research institutions in France or abroad, or from public or private research centers.
L'archive ouverte pluridisciplinaire HAL, est destinée au dépôt et à la diffusion de documents scientifiques de niveau recherche, publiés ou non, émanant des établissements d'enseignement et de recherche français ou étrangers, des laboratoires publics ou privés. 


\title{
Towards contact integration for III-V/Silicon heterogeneous Photonics devices
}

\author{
E. Ghegin ${ }^{1,2,3}$, Ph. Rodriguez ${ }^{2}$, F. Nemouchi ${ }^{2}$, Ch. Jany ${ }^{2}$, M. Brihoum ${ }^{2}$, A. Halimaoui ${ }^{1}$, I. Sagnes ${ }^{3}$, B. Szelag ${ }^{2}$ \\ ${ }^{1}$ STMicroelectronics, \\ 850 rue Jean Monnet, \\ 38926 Crolles Cedex, France. \\ ${ }^{2}$ Univ. Grenoble Alpes, \\ F-38000 Grenoble; CEA, LETI, MINATEC Campus, \\ F-38054 Grenoble, France.
}

\author{
${ }^{3}$ CNRS-LPN, \\ Route de Nozay, 91460 Marcoussis. \\ Contact E-mail : elodie.ghegin@st.com
}

\begin{abstract}
Silicon photonics is of great interest as it opens the way to large bandwidth and high data rates. A pioneer Silicon photonics scheme consists in integrating III-V lasers on the SOI substrates containing the passive components. However, key developments are necessary to co-integrate III-V devices with CMOS very large scale integration (VLSI). In this paper we propose a CMOS-compatible integration scheme of contacts (i.e. semiconductor metallization and plug) on III-V surfaces taking into account the limitations fixed by the operating laser device. Based on metallurgical, morphological, optical and electrical studies, processes are submitted and reviewed for the purpose of forming stable and reproducible contacts with low resistivity in a 200 millimeters fab line.
\end{abstract}

Keywords-Silicon Photonics, Heterogeneously integrated IIIV laser on Silicon, Contact integration

\section{INTRODUCTION}

Allowing data rates beyond what electronic component can offer Silicon Photonics have been identified as one promising paradigm. However, while silicon is of huge interest for the making of passive components, its indirect band gap prevents it from being an efficient light emitter. As a consequence, the making of the photons' source requires the use of different materials. An innovative solution consists in integrating III-V lasers on SOI (Silicon on Insulator) substrates which support the passive components such as the waveguide (Fig. 1) [1], [2]. To produce such a pioneer device, one of the most critical developments relates to the integration of the contacts that are key to electrically pump the III-V laser. Indeed, in current Photonics devices the III-V laser is external and coupled to the passive components thanks to an optical fiber. The contacts present on these external lasers are comprised of Pt, $\mathrm{Pd}$ or $\mathrm{Au}$ multilayers and based on a lift-off integration [3], [4], [5]. Such a scheme is not conform to the "on-SOI-integrated-laser" standards. In order to fulfil the Silicon Photonics requirements, the innovative contacts (i.e. metallization and plug) on n-InP and p-InGaAs must:

- be integrated thanks to 200 millimeters front-end compatible processes which exclude any lift-off or related processes;

- be comprised of front-end compatible materials only, such as Ni, Ti and their alloys; be feasible at low thermal budget $\left(\mathrm{T}<450{ }^{\circ} \mathrm{C}\right)$ in order not to degrade the active region of the laser composed of multi quantum wells (MQW);

- present a contact resistivity lower than $10^{-6} \Omega . \mathrm{cm}^{2}$. A higher contact resistivity would cause a local heating that may give rise to a wavelength shift of the produced photons.

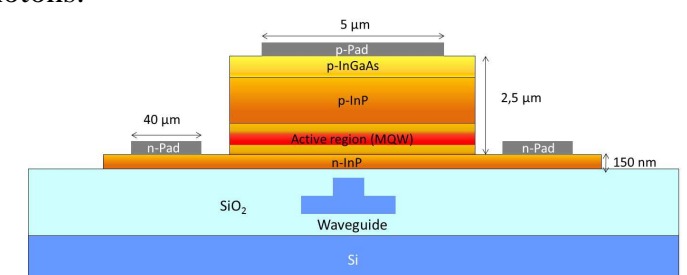

Fig. 1: Schematic representation of a III-V Laser integrated on an SOI substrate which supports the passive photonics components in the frame of Silicon Photonics

In this paper, we review and evaluate the various technological solutions for integrating contacts that meet the previously listed requisites.

\section{CONTACTS INTEGRATION SCHEME}

To identify the most relevant processes and to develop them, morphological and electrical test vehicles such as transmission line model structures (TLM) and cross bridge kelvin resistors (CBKR) were integrated either on n-InP or on p-InGaAs surfaces (Fig. 2).

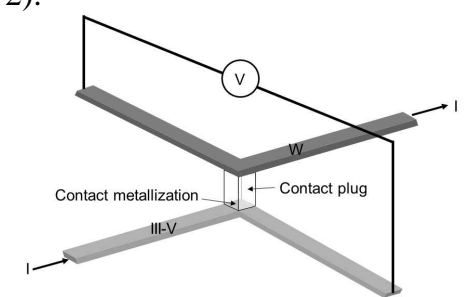

Fig. 2: Schematic representation of a cross bridge kelvin resistor (CBKR) used for the acquisition of $\mathrm{I}(\mathrm{V})$ characteristics and for specific contact resistivity extraction

Two inches III-V substrates were reported on 200 millimeters silicon substrates enabling the processing of the wafers in an industrial 200 millimeters fab line. The process flow related to the proposed and reviewed integration is schematically shown in Fig. 3. 


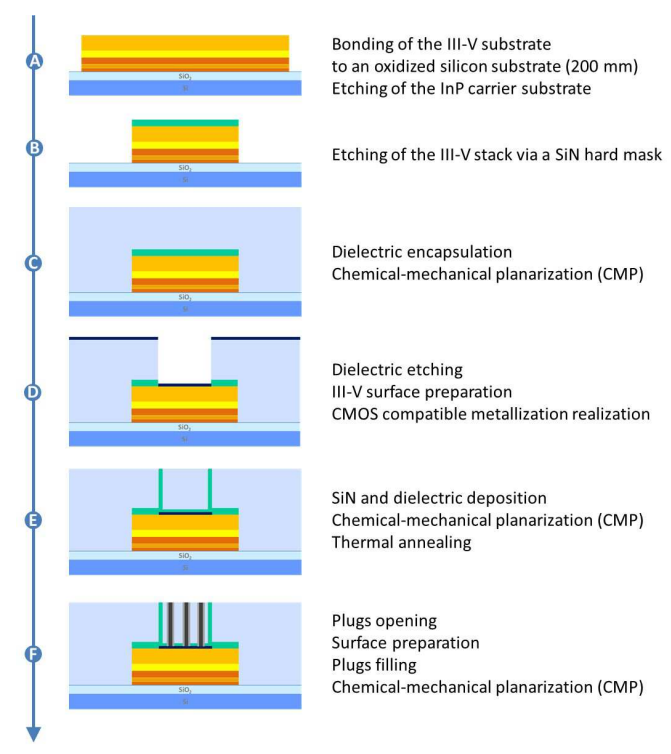

Fig. 3: CMOS compatible process flow for the integration of the contacts on a III-V epitaxy in the framework of Silicon Photonics

\section{DETAILED DESCRIPTION OF THE PROCESS FLOW}

\section{A. Transfert of the III-V stack on the silicon substrate}

The III-V wafers are transferred on oxidized silicon wafers thanks to a direct bonding process and the III-V carrier substrate is etched up to the active layers, i.e. $\mathrm{n}$-InP or $\mathrm{p}$ InGaAs as displayed in Fig. 4.

a)

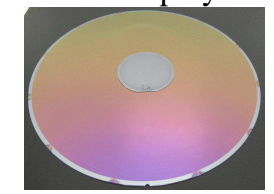

b)

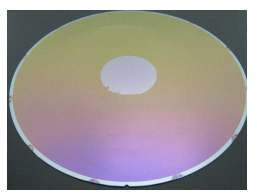

Fig. 4: Picture of a 2 inches III-V substrate (a) after its bonding to a 200 millimeters oxidized silicon substrate and (b) after the etching of the III-V carrier substrate

\section{B. Ecthing of the III-V stack via a SiN hard mask}

The etching of the III-V stack requires the use of a SiN hard mask which deposition temperature and intrinsic stress must be kept as low as possible (i.e. $\mathrm{T} \leq 300{ }^{\circ} \mathrm{C}$ and $\sigma \leq 100 \mathrm{MPa}$ ) in order not to deteriorate the III-V surfaces on which the contacts will be integrated. The inductively coupled plasma process (ICP) used for this III-V etching provides high etch rates and leaves smooth and vertical sidewalls (Fig. 5). Note that when reporting full two-inch substrates a great surface of the expensive III-V stack is lost during the etching. In order to minimize the material loss, a solution consists in bonding millimeter-scale dies on the SOI substrate thanks to dedicated holders before the etching step.

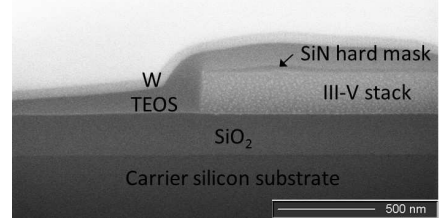

Fig. 5: FIB/SEM image of a III-V stack after its dry etching via a SiN hard mask. Note that the TEOS and W were used for the FIB etching only.

\section{Dielectric encapsulation}

In order to electrically isolate the contacts regions, the whole structure is encapsulated by a dielectric compound. The choice of the dielectric nature is crucial because of its vicinity from the laser's active region in the device. A low transmittance of this material at the laser wavelength would cause unwanted optical losses; a low thermal conductivity $(\sigma)$ wouldn't enable a proper evacuation of the heat produced by the operating laser.

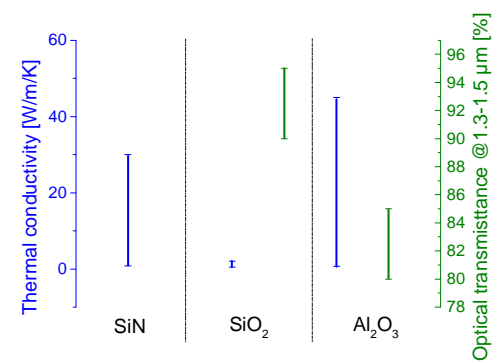

Fig. 6: Thermal conductivity and optical transmittance at 1.3-1.5 $\mu \mathrm{m}$ of $\mathrm{SiN}, \mathrm{SiO}_{2}$ and $\mathrm{Al}_{2} \mathrm{O}_{3}$

As indicated in Fig. 6, $\mathrm{Al}_{2} \mathrm{O}_{3}$ appears to be the best compromise for the laser encapsulation. Because of the present topography, a flattening of the surface must be made thanks to a chemical-mechanical planarization (CMP). The planarization of the $\mathrm{Al}_{2} \mathrm{O}_{3}$ being challenging, the deposition of stacks combining $\mathrm{SiO}_{2}, \mathrm{Al}_{2} \mathrm{O}_{3}$ and $\mathrm{SiN}$ was retained as the most adapted solution for the dielectric encapsulation.

\section{Contact metallization}

\section{1) Cavities opening and III-V surface preparation}

The opening of the cavities in the dielectric stack is one of the most sensitive step in this integration flow as it must not deteriorate the n-InP or $\mathrm{p}$-InGaAs surface where the ohmic contacts will be formed. For this purpose, studies are being conducted to determine the most appropriate $\mathrm{SiN}$ etching process. The III-V surface being very reactive when exposed to oxygen, a two-step surface preparation is carried out to suppress contaminants and oxides. The first step consists in a wet surface preparation; the second in a plasma treatment.

(i) We developed a scheme combining diluted $\mathrm{HCl}$ and $\mathrm{Ar}$ or He plasma treatments to remove oxides on InGaAs without inducing any morphological damage on these surfaces [6], [7]. (ii) We demonstrated that the preparation of InP surfaces is more delicate as concentrated $\mathrm{HCl}$ increases significantly its roughness by anisotropically etching it (Fig. 7). We also highlighted that an Ar preclean removes efficiently the oxides present on such surfaces but modifies their crystallinity and stoichiometry [6], [8]. On the contrary, diluted $\mathrm{H}_{2} \mathrm{SO}_{4}$ and $\mathrm{HCl}$ solutions combined with a He preclean seems to be a more adapted compromise for the preparation of InP surfaces (Fig. 7) [6].

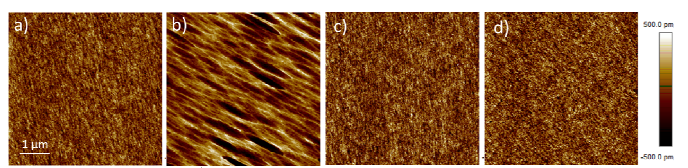

Fig. 7: AFM scans of a InP surface (a) before and after a wet surface preparation in (b) $\mathrm{HCl}: \mathrm{H}_{2} \mathrm{O}$ (1:2) (c) $\mathrm{HCl}: \mathrm{H}_{2} \mathrm{O}$ (1:11) (d) $\mathrm{H}_{2} \mathrm{SO}_{4}: \mathrm{H}_{2} \mathrm{O}$ (1:9); The Root Mean Square roughness is (a) $<0.2 \mathrm{~nm}$ (b) $1.7 \mathrm{~nm}$ (c) $<0.2 \mathrm{~nm}$ (d) $<0.2 \mathrm{~nm}$ 
2) CMOS-compatible contact metallisation

Two strategies can be followed for the formation of the CMOS-compatible metallization: (i) One can choose to deposit directly the metallization of interest on the III-V surface. The stabilization of the phase(s) is achieved by mean of an annealing process. (ii) One can also choose to deposit a metal and to perform a thermal treatment for the purpose of forming an intermetallic compound by solid state reaction with the III-V. Metallurgical studies were conducted on the $\mathrm{Ni} / \mathrm{InGaAs}$ system and showed the formation of a unique hexagonal phase [9]. A similar study on the $\mathrm{Ni} / \mathrm{InP}$ system underlined the appearance of various phases $\left(\mathrm{Ni}_{2} \mathrm{P}, \mathrm{Ni}_{3} \mathrm{P}\right.$ and $\mathrm{Ni}_{2} \mathrm{InP}$ ) based on different applied thermal treatments and the formation of the In phase from $350{ }^{\circ} \mathrm{C}$ (Fig. 8) [8].

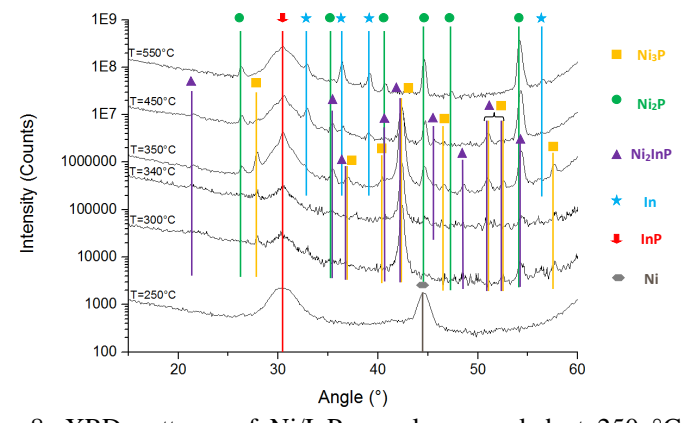

Fig. 8: XRD patterns of $\mathrm{Ni} / \mathrm{InP}$ samples annealed at $250{ }^{\circ} \mathrm{C}, 300^{\circ} \mathrm{C}$, $340^{\circ} \mathrm{C}, 350{ }^{\circ} \mathrm{C}, 450{ }^{\circ} \mathrm{C}$ and $550{ }^{\circ} \mathrm{C}$ for 60 seconds (RTP). A $2^{\circ}$ offset on the incident beam was applied in order to minimize the InP substrate contribution

The two contacts (i.e., on n-InP and p-InGaAs) being sequentially integrated in the laser device, thermal budget constraints have to be respected during the making of the second-stage contacts. The thermal stability of the Ni-InGaAs intermetallic was studied and exhibits strong restrictions (Fig. 9).

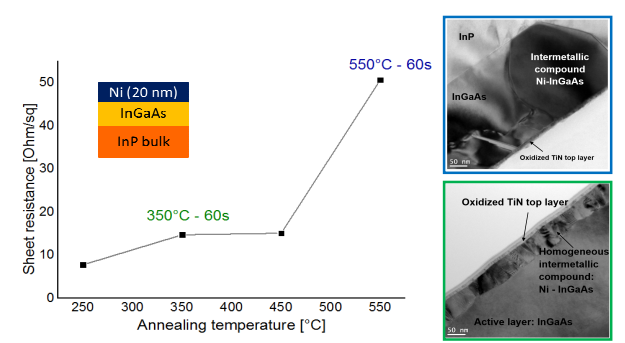

Fig. 9: Evolution of the sheet resistance in a $\mathrm{Ni} / \mathrm{InGaAs}$ system after various thermal treatments and corresponding TEM pictures

\section{E. , F. Metallization encapsulation and Plug integration}

Subsequently to the dielectric stack deposition, cavities are opened and a surface preparation of the metallization is carried out. A diffusion barrier layer usually composed of CVD-TiN (Chemical Vapor Deposition) is deposited on the walls of the cavities. An alternative consists in depositing a CVD-F-less $\mathrm{W}$ which is of great interest for its electrical properties at low thicknesses (Fig. 10). This attribute opens the way for lowering the plug resistivity which is essential to minimize the overall resistance.

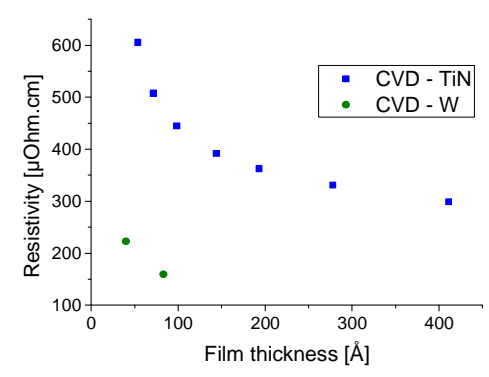

Fig. 10: Resistivity of CVD-TiN and CVD F-less $\mathrm{W}$ as a function of the films thicknesses

Regardless the choice of the diffusion barrier composition, the cavities are then filled with W. A final CMP ends the integration of the CMOS-compatible contacts as represented in Fig. 3, step F.

\section{CONCLUSION}

The integration of III-V lasers on SOI substrates appears to be a promising but challenging architecture for innovative Silicon Photonics devices. In this paper the main roadblocks towards contact integration requiring developments and key studies were clearly highlighted. Thanks to metallurgical, morphological, optical and electrical studies we were able to propose and develop schemes and processes opening the way to a CMOS-compatible contact integration on III-V surfaces.

\section{ACKNOWLEDGMENT}

The authors would like to thank B. Previtali, T. Card, N. Chevalier (CEA-LETI) and J. L. Lábár (MTA EK MFA) for their help during this study. This work was funded thanks to the French national program 'programme d'Investissements d'Avenir, IRT Nanoelec' ANR-10-AIRT-05.

\section{REFERENCES}

[1] B. Ben Bakir et al., "Heterogeneously integrated III-V on silicon lasers," Meeting Abstracts, vol. MA2014-02, no. 34, p. 1724, 2014.

[2] G.-H. Duan et al., "Hybrid III-V on silicon lasers for photonic integrated circuits on silicon," J. Sel. Top. Quantum Electron, vol. 20, pp. 158-170, July 2014.

[3] A. Baca et al., "A survey of ohmic contacts to III-V compound semiconductors,” Thin Solid Films, vol. 308-309, pp. 599-606, 1997.

[4] A. Katz et al., "Au/Pt/Ti contacts to p- $\mathrm{In}_{0.43} \mathrm{Ga}_{0.47} \mathrm{As}$ and n-InP layers formed by a single metallization common step and rapid thermal processing," J. Appl. Phys, vol. 68, no. 3, p. 1123, 1990.

[5] G. Stareev et al., "A controllable mechanism of forming extremely low-resistance nonalloyed ohmic contacts to group III-V compound semiconductors," J. Appl. Phys, vol. 74, no. 12, p. 7344, 1993.

[6] P. Rodriguez et al., "Cleaning of InGaAs and InP layers for Nanoelectronics and Photonics contact technology applications," ECS Transactions, vol. 69, no. 8, pp. 251-259, 2015.

[7] P. Rodriguez et al., "In situ cleaning of InGaAs surfaces prior to low contact resistance metallization," Microelectronic Engineering, doi:10.1016/j.mee.2015.11.013, 2015.

[8] E. Ghegin et al., "Phase formation in the $\mathrm{Ni} / \mathrm{InP}$ contacts for heterogeneous III/V-Silicon photonic integration," Microelectronic Engineering, doi:10.1016/j.mee.2015.12.008, 2015.

[9] S. Zhiou et al., "Influence of the substrate on the solid-state reaction of ultra-thin $\mathrm{Ni}$ film with a $\mathrm{In}_{0.43} \mathrm{Ga}_{0.47} \mathrm{As}$ under-layer by means of full 3D reciprocal space mapping," in IITC/MAM 2015 IEEE International, pp. 63-66, May 2015. 